\title{
Nitric oxide metabolite changes in gentamicin-induced nephrotoxicity; the effects of antioxidant vitamins
}

\author{
Tahereh Safari ${ }^{1 *}$, Saideh Miri ${ }^{1}$, Fateme Kourkinejad Gharaei ${ }^{2}$, Athareh NazriPanjaki ${ }^{2}$, Fatemeh Saeidienik ${ }^{1}$, \\ Hossein Bagheri ${ }^{3}$, Mehdi Nematbakhsh ${ }^{4}$ \\ ${ }^{1}$ Department of Physiology, Zahedan University of Medical Sciences, Zahedan, Iran \\ ${ }^{2}$ Student Research Committee, Zahedan University of Medical Sciences, Zahedan, Iran \\ ${ }^{3}$ Department of Medical English, Zahedan University of Medical Sciences, Iran \\ ${ }^{4}$ Water and Electrolytes Research Center \& Department of Physiology, Isfahan University of Medical Sciences, Isfahan, Iran
}

\section{A R T I C L E I N F O}

\section{Article Type:}

Original

\section{Article History:}

Received: 1 October 2017

Accepted: 18 November 2017

Published online: 6 December 2017

\section{Keywords:}

Gentamicin

Nitrite

Antioxidant vitamins

Gender differences

\begin{abstract}
A B S T R A C T
Introduction: Nitric oxide (NO) has some important roles in endothelial functioning and renal hemodynamics. Based on previous studies, NO function is different in both genders. Probably, antioxidant vitamins, as free radical scavengers, have some protective effects on renal injury.

Objectives: This study aims to search the possible antioxidant effects on nitrite level in both sexes.

Materials and Methods: The rats were divided into 8 groups each including both male and female ones; The categories include 1) gentamicin treated, 2) gentamicin and vitamin E-treated, 3) gentamicin and vitamin C-treated, 4) gentamicin plus vitamin E and C treated. Nine days after administering drugs, blood samples were collected from the heart. The level of urea, creatinine $(\mathrm{Cr})$, and nitrite were measured in the animals serum. Also, nitrite level was measured in the homogenized kidney tissue.

Results: Gentamicin, in male and female rats enhanced serum urea and Cr levels significantly at the level of $P<0.05$. In the presence of the vitamins $\mathrm{E}$ and $\mathrm{C}$ individually urea and Cr levels decreased significantly too. After GM administration serum nitrite level was higher in female than male rats at the statistically significant level. Vitamin E increased serum nitrite level in male and female rats in comparison with GM group. Similarly, the vitamins enhanced kidney nitrite level which was significantly higher in male than female animals.

Conclusion: This study shows that administrating vitamin $\mathrm{E}$ and $\mathrm{C}$ could individually have stronger effect on nitrite more prominently among male rats.
\end{abstract}

Implication for health policy/practice/research/medical education:

In this experimental study, 68 adult Wistar rats made the subject of the study. Administration of vitamin $\mathrm{E}$ and $\mathrm{C}$, in an individual manner, can have some more favorable effects on urea, creatinine and nitrite level in GM nephrotoxicity than their coadministration. On the other hand, there is a gender difference, in response to vitamin $\mathrm{E}$ and $\mathrm{C}$ in which male gender responded more favorably to the antioxidant vitamins.

Please cite this paper as: Safari T, Miri S, Kourkinejad Gharaei F, NazriPanjaki A, Saeidienik F, Bagheri H, et al. Nitric oxide metabolite changes in gentamicin-induced nephrotoxicity; the effects of antioxidant vitamins. J Renal Inj Prev. 2018;7(3):201-205. doi: $10.15171 /$ jrip. 2018.47

\section{Introduction}

Nitric oxide (NO) is produced by NO syntheses from 1-arginine (1-3). Many studies have shown that NO production in female during pregnancy and after estrogen administration is more than male $(4,5)$. This mediator has some important roles in endothelial functioning and renal hemodynamics $(1,2)$. Studies show that NO deficiency causes enhancing vascular resistance and hypertension (6). Previous studies have also revealed that estrogen increases NO production. On the other hand, researchers have reported that $\mathrm{NO}$ release in response to acetylcholine is more observed among females $(7,8)$.

$\mathrm{GM}$, as an aminoglycoside antibiotic, is widely used in gram-negative infections (9-11). It is worth mentioning 
that nephrotoxicity is, unfavorably, the most common side effect of GM $(12,13)$. Probably, GM, via increasing free radicals (14) decreases the level of antioxidants and accelerates the renal damage $(15,16)$. On the other hand, antioxidant vitamins, as free radical scavengers, have some important effects on renal diseases (17). Also, these vitamins can generally increase nitrite level (18).

Enormous studies have shown some contradictory effects on serum and kidney level of NO. For example, Sadeghi et al reported that after administration of GM, serum and kidney levels of NO decreased (19), while Morsy et al documented that GM increased nitrite levels (20).

\section{Objectives}

Based on these facts, the following questions are raised here; 1 ) are there any differences in serum and kidney level of nitrite after GM administration in both genders and 2) are there any differences in response to antioxidant vitamins between male and female rats. Regarding these questions, we sought to examine whether antioxidant vitamins have any different effects on serum and kidney nitrite between the two sexes? To test this hypothesis, male and female rats were selected to be evaluated for any possible effects of antioxidant vitamins on serum and kidney nitrite level.

\section{Materials and Methods \\ Animals}

In this research, 68 adult Wistar rats were used from the animal center of Zahedan University of Medical Sciences. The female ones weighed $178.0 \pm 2.5 \mathrm{~g}$ and the male ones $197.4 \pm 7.2 \mathrm{~g}$ on average. These rats were housed at a temperature of $23-25^{\circ} \mathrm{C}$. They had free access to water and rat chow. They were also acclimatized to their diet for at least one week prior to the experiment. Moreover, the experimental procedure of the research was approved by the Zahedan University Medical Sciences Ethics Committee.

\section{Drugs}

Gentamicin was purchased from Caspian Company in Iran, vitamin E and C were obtained from Sigma (St. Louis, MO, USA) and Scharlab S.L Spain, respectively.

\section{Experimental protocol}

The animals were randomly assigned to eight groups each including both male and female ones. The first and second groups, each including nine rats, received gentamicin (80 $\mathrm{mg} / \mathrm{kg} / \mathrm{d}$ ) for 9 days (21). Similarly, the third and fourth groups, each including nine rats, received a regular dose of gentamicin $(80 \mathrm{mg} / \mathrm{kg} / \mathrm{d})+$ vitamin $\mathrm{E}(1 \mathrm{~g} / \mathrm{kg} / \mathrm{d})$ for 9 days (22). The fifth and sixth groups, each consisting of eight animals, obtained a continuous dose of gentamicin $(80 \mathrm{mg} / \mathrm{kg} / \mathrm{d})+$ vitamin C $(250 \mathrm{mg} / \mathrm{kg} / \mathrm{d})$ for 9 days (23). The seventh and eighth groups, each consisting of eight animals, obtained a dose of gentamicin + vitamin E and $\mathrm{C}$, simultaneously for duration of 9 days.
On the next day, after the end of drug administration, blood samples were taken from the heart of each animal. The serum levels of urea, creatinine $(\mathrm{Cr})$ and nitrite were measured. During the study, the animals' weights were measured and recorded on a daily basis. Also, kidney nitrite level was measured in the homogenized tissue.

\section{Measurements}

The levels of serum $\mathrm{Cr}$ and urea were determined using quantitative diagnostic kits (Pars Azmoon, Iran). The level of nitrite (stable NO metabolite) in serum and supernatant was measured using a colorimetric assay kit (Promega Corporation, USA) that involves the Griess reaction.

\section{Ethical issues}

The research followed the tenets of the Declaration of Helsinki. This project was approved by Ethics Committee of Zahedan University of Medical. Prior to the experiment, the protocols were confirmed to be in accordance with the guidelines of Animal Ethics Committee of Zahedan University of Medical Sciences (code\# 7475).

\section{Statistical analysis}

Data are expressed as mean \pm SEM. The levels of urea, $\mathrm{Cr}$, nitrite and kidney weights were analyzed by one-way analysis of variance (ANOVA) followed by the Tukey test. These parameters were compared in each group between male and female by t-Student test. $P$ values less than 0.05 were considered statistically significant using SPSS version 16 for the data analysis

\section{Results}

According to this study, the comparison of kidney weight in all groups did not show any significant difference in male and female rats.

GM $80 \mathrm{mg} / \mathrm{kg}$ for 9 days, in male and female rats enhanced serum urea and $\mathrm{Cr}$ levels at the significant level of $\mathrm{P}<0.05$, which approves kidney damage (Table 1). In the presence of vitamin $\mathrm{E}$ and $\mathrm{C}$ individually, urea and $\mathrm{Cr}$ levels were decreased significantly in both genders. The concomitant use of antioxidant vitamins does not have any effect on urea and Cr levels (Table 1).

In response to GM, serum nitrite level was significantly higher in female rats than male rats (Figure 1). In the presence of vitamin E, serum nitrite level has significantly increased in male and female rats in comparison with GM group, that also shows a significant difference between both gender. Vitamin $\mathrm{C}$ alone and co-administration of antioxidant vitamins had no observable effect on serum nitrite level in male rats but in female rats this effect was significant and decreased nitrite level (Figure 1).

The comparison of the kidney level of nitrite in the groups treated by GM did not show a significant difference between both genders. Following the administration of antioxidant vitamins, kidney nitrite level increased compared with GM group, at the statistically significant level (Figure 2). It is worth mentioning that in male rats, 
Table 1. Blood urea and creatinine in male and female rats

\begin{tabular}{lcccc}
\hline & \multicolumn{2}{c}{ Urea $(\mathrm{mg} / \mathrm{dL})$} & \multicolumn{2}{c}{ Creatinine $(\mathrm{mg} / \mathrm{dL})$} \\
\cline { 2 - 5 } Group & Male & Female & Male & \multicolumn{1}{c}{ Female } \\
\hline GM & $116.94 \pm 4.18^{*}$ & $132.14 \pm 2.36^{*}$ & $1.5 \pm 0.25^{*}$ & $0.14 \pm 0.25^{*}$ \\
G+E & $60.62 \pm 2.89$ & $64.14 \pm 6.93$ & $1.42 \pm 0.20$ & 09 \\
G+C & $58.93 \pm 3.37$ & $56.80 \pm 3.18$ & $1.62 \pm 0.1$ & $0.81 \pm 0.04$ \\
G+E+C & $110.31 \pm 5.69$ & $127.42 \pm 8.47$ & $1.21 \pm 0.19$ \\
\hline
\end{tabular}

All groups received gentamicin $80 \mathrm{mg} / \mathrm{kg} / \mathrm{d}(\mathrm{GM}), \mathrm{GM}+$ vitamin $\mathrm{E} 1 \mathrm{~g} / \mathrm{kg} / \mathrm{d}(\mathrm{G}+\mathrm{E}), \mathrm{GM}+$ vitamin C $250 \mathrm{mg} / \mathrm{kg} / \mathrm{d}(\mathrm{G}+\mathrm{C})$ and GM + vitamin E and C (G +

$\mathrm{E}+\mathrm{C})$ for 9 days. * indicates significant difference between $\mathrm{GM}$ group with $\mathrm{G}+\mathrm{E}$ and $\mathrm{G}+\mathrm{C}$ groups $(P<0.05)$. Values are expressed as mean $\pm \mathrm{SEM}$.

in response to vitamins treatment, the increase of kidney nitrite level was higher than that of female rats $(P<0.05)$.

\section{Discussion}

There are three main findings in this research are discussed in the following. Firstly, the administration of vitamin $\mathrm{E}$ and $\mathrm{C}$ can, individually, decrease urea and $\mathrm{Cr}$ level in both genders. Secondly, vitamin E can by itself increase serum nitrite level in male and female rats; while this increase was higher in female rats. Thirdly, in the presence of antioxidant vitamins, kidney nitrite level enhanced in comparison with that of GM group, but it was significantly higher in male rats.

Previous studies have documented that antioxidant vitamins with increase of $\mathrm{NO}$ synthase activity can enhance NO level, which is consistent with our results. They have also reported that the vasodilator effect of NO improves the blood flow which can, in its own turn, decrease tissue damage (24). In another study, Jilanchi et al have shown that, in cisplatin nephrotoxicity, vitamin E modified BUN and Cr level in male rates; while this effect was not observed in female rats (22). Actually, antioxidant vitamins act as free radical scavengers, therefore, the decrease of kidney damage can improve BUN and Cr level. In their research, the increased serum level of nitrite in female rats can be due to the higher level of inducible NO

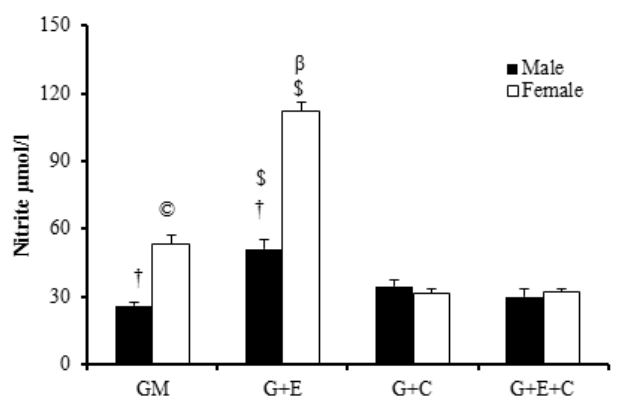

Figure 1. Serum Nitrite level, The groups received gentamicin $80 \mathrm{mg} / \mathrm{kg} / \mathrm{d}(\mathrm{GM}), \mathrm{GM}+$ vitamin E, $1 \mathrm{~g} / \mathrm{kg} / \mathrm{d}(\mathrm{G}+\mathrm{E}), \mathrm{GM}$ +vitamin $C, 250 \mathrm{mg} / \mathrm{kg} / \mathrm{d}(\mathrm{G}+\mathrm{C})$ and $\mathrm{GM}+$ vitamins $E$ and $C(G+E+C)$ for 9 days. The symbols indicate significant difference; $\$$ from GM group, $\beta$ from $\mathrm{G}+\mathrm{C}$ or $\mathrm{G}+\mathrm{E}+\mathrm{C}$ groups, $\odot$ from $\mathrm{G}+\mathrm{E}, \mathrm{G}+\mathrm{C}$ or $\mathrm{G}+\mathrm{E}+\mathrm{C}$ groups in the same gender $(P<0.05)$. The symbol $\dagger$ indicates significant difference from female rats in the same group $(P<0.05)$. synthase (iNOS) and the presence of estrogen in female rats (22). Estrogen enhanced iNOS expression which in its own turn increases NO level. Normally, Estrogen induces oxidative stress which increases nitrite level (25), that this is true with our study.

The results of the study by Sadeghi et al, have shown that GM reduces kidney nitrite level. They have also reported that treatment with pomegranate flower extract improves BUN and Cr level and decreases renal damage (19).

$\mathrm{NO}$, as an important biologic agent is synthesized by three types of NO synthase isoform consisting of neural NOS (nNOS), endothelial NOS (eNOS) and inducible NOS (iNOS) $(26,27)$. Our study shows that the decrease of nitrite resulted from GM-treatment, was improved by vitamin $\mathrm{E}$ and $\mathrm{C}$, hence it could compensate for the decrease of nitrite. Another study has reported that antioxidant vitamins can elicit $\mathrm{NO}$ level and improve endothelial functioning (28).

Contrary to our findings, Morsy at al, documented that GM could increase NO level (20). Other studies reported that NO does not have any important role in renal hemodynamic. However, NO can regulate the functioning of renal tubules (29). In this regard, Narita et al have shown that lowering of $\mathrm{NO}$ can positively affect renal damage and glomerulosclerosis (30). Additionally, there were reports that NO has an important role in acute renal failure and induced kidney damage by reaction with superoxide and proxy nitrite production (31) which is inconsistent with

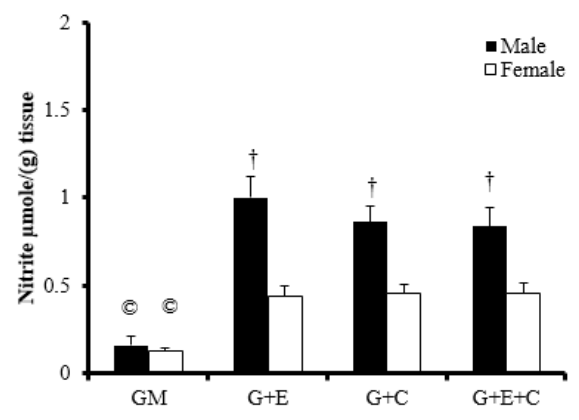

Figure 2. Kidney Nitrite level, The groups received gentamicin $80 \mathrm{mg} / \mathrm{kg} / \mathrm{d}$ (GM), GM+ vitamin E, $1 \mathrm{~g} / \mathrm{kg} / \mathrm{d}(\mathrm{G}+\mathrm{E}), \mathrm{GM}+$ vitamin $C, 250 \mathrm{mg} / \mathrm{kg} / \mathrm{d}(\mathrm{G}+\mathrm{C})$ and $\mathrm{GM}+$ vitamins $E$ and $C(G+E+C)$ for 9 days. The symbol (C) indicates significant difference from $\mathrm{G}+\mathrm{E}, \mathrm{G}+\mathrm{C}$ or $\mathrm{G}+\mathrm{E}+\mathrm{C}$ groups in the same gender $(P<0.05)$. The symbol $\dagger$ indicates significant difference from female rats in the same group $(P<0.05)$. 
the findings of our study.

Based on the other studies, deficiency of NO causes vascular contraction and increase in blood pressure. Probably, during its shortages, the increase of NO will have favorable effects (24). In this regard, Baylis reported that different paths which reduce NO level can play a pivotal role in chronic kidney diseases. This NO decrease has connection with its decline of production (32). Reckelhof et al illustrated that although eNOS protein and mRNA level in kidney are observed more in female than male rats. However, the functional response to NO synthase inhibition was more in male than female animals (4). In our study, this effect may lead to a higher sensitivity to GM which may result in higher kidney nitrite levels in male animals. Other studies have also shown that the expression of nNOS between two genders has significant differences. While this induction of hypertension did not have any effect on nNOS but stimulated eNOS expression in male rats (33).

\section{Conclusion}

Results of this study show that the administration of vitamin $\mathrm{E}$ and $\mathrm{C}$, in an individual manner, can have some more favorable effects on urea, $\mathrm{Cr}$, and nitrite level in GM nephrotoxicity than their co-administration. On the other hand, there is a gender difference, in response to vitamin $\mathrm{E}$ and $\mathrm{C}$ in which male gender responded more favorably to the antioxidant vitamins.

\section{Authors' contribution}

TS and MN designed, conducted, supervised and analyzed the research and prepared the first draft of manuscript. $\mathrm{SM}, \mathrm{KF}, \mathrm{AN}$ and FS participated in the performance of the research and collected the data. HB participated in the writing and editing of the paper.

\section{Conflicts of interest}

The authors declare that they have no conflicts of interest.

\section{Ethical considerations}

Ethical issues (including plagiarism, data fabrication, double publication) have been completely observed by the authors.

\section{Funding/Support}

The research was supported by Zahedan University of Medical Sciences (Grant \# 7475).

\section{References}

1. Bauer V, Sotníková R. Nitric oxide-the endotheliumderived relaxing factor and its role in endothelial functions. Gen Physiol Biophys. 2010;29;4:319-40.

2. Schmidt HH, Walter U. NO at work. Cell. 1994;78;6:919-25.

3. CacanyiovaS. Thevasoactiverole of nitric oxide: physiological and morphological aspects. Curr Pharm Biotechnol. 2011;12;9:1294-304. doi: 10.2174/138920111798280992.

4. Reckelhoff JF, Hennington BS, Moore AG, Blanchard EJ,
Cameron J. Gender differences in the renal nitric oxide (NO) system. Am J Hypertens. 1998;11;1:97-104.

5. Ji H, Pesce C, Zheng W, Kim J, Zhang Y, Menini S, et al. Sex differences in renal injury and nitric oxide production in renal wrap hypertension. Am J Physiol Heart Circ Physiol. 2005;288;1:H43-7. doi: 10.1152/ajpheart.00630.2004.

6. Reckelhoff MR. Role of endothelial derived nitric oxide in the control of the renal microvasculature in aging male rats. Am J Phisiol. 1993;265:R1126-R31.

7. Kauser K, Rubanyi GM. Gender difference in bioassayable endothelium-derived nitric oxide from isolated rat aortae. Am J Physiol. 1994;267;6:H2311-H7.

8. Kauser K, Rubanyi GM. Gender difference in endothelial dysfunction in the aorta of spontaneously hypertensive rats. Hypertension. 1995;25;4:517-23.

9. Weinstein M, Wagman G, Oden E, Marquez J. Biological activity of the antibiotic components of the gentamicin complex. J Bacteriol. 1967;94;3:789.

10. Nagabhushan TL, Turner WN, Daniels PJ, Morton JB. Gentamicin antibiotics. 7. Structures of the gentamicin antibiotics A1, A3, and A4. J Org Chem. 1975;40;19:2830-4.

11. Regis D, Sandri A, Samaila E, Benini A, Bondi M, Magnan B. Release of gentamicin and vancomycin from preformed spacers in infected total hip arthroplasties: measurement of concentrations and inhibitory activity in patients' drainage fluids and serum. ScientificWorldJournal. 2013;2013. doi: $10.1155 / 2013 / 752184$.

12. Hariprasad G, Kumar M, Rani K, Kaur P, Srinivasan A. Aminoglycoside induced nephrotoxicity: molecular modeling studies of calreticulin-gentamicin complex. J Mol Model. 2012;18;6:2645-52. doi: 10.1007/s00894-011-12898.

13. Wargo KA, Edwards JD. Aminoglycoside-induced nephrotoxicity. J Pharm Pract. 2014;27;6:573-7. doi: $10.1177 / 0897190014546836$.

14. Sha S-H, Schacht J. Stimulation of free radical formation by aminoglycoside antibiotics. Hear Res. 1999;128;1:112-8.

15. Mazzon E, Britti D, De Sarro A, Caputi AP, Cuzzocrea S. Effect of $\mathrm{N}$-acetylcysteine on gentamicin-mediated nephropathy in rats. Eur J Pharmacol. 2001;424;1:75-83.

16. Maldonado PD, Barrera D, Rivero I, Mata R, MedinaCampos ON, Hernández-Pando R, et al. Antioxidant S-allylcysteine prevents gentamicin-induced oxidative stress and renal damage. Free Radic Biol Med.2003;35;3:317-24.

17. Devasagayam T, Tilak J, Boloor K, Sane KS, Ghaskadbi SS, Lele R. Free radicals and antioxidants in human health: current status and future prospects. Japi. 2004;52;10:794804.

18. Li X, Long $\mathrm{Y}$, Fang X, Liu X. Effect of vitamin $\mathrm{C}$ and $\mathrm{E}$ on antioxidative enzyme, NOS activity and NO contents in hippocampus of rats with lead poisoning. Zhejiang Da Xue Xue Bao Yi Xue Ban. 2008;37;2:189-92.

19. Sadeghi F, Nematbakhsh M, Noori-Diziche A, Eshraghi-Jazi F, Talebi A, Nasri H, et al. Protective effect of pomegranate flower extract against gentamicin-induced renal toxicity in male rats. J Renal Inj Prev. 2015;4;2:45. doi: 10.12861/ jrip.2015.10.

20. Morsy MA, Ibrahim SA, Amin EF, Kamel MY, Rifaai RA, Hassan MK. Sildenafil ameliorates gentamicin-induced nephrotoxicity in rats: role of iNOS and eNOS. J Toxicol. 2014;2014:489382. doi: 10.1155/2014/489382.

21. Can C, Şen S, Boztok N, Tuğlular I. Protective effect of oral $\mathrm{L}$-arginine administration on gentamicin-induced renal 
failure in rats. Eur J Pharmacol. 2000;390(3):327-34.

22. Jilanchi $S$, Nematbakhsh $M$, Bahadorani $M$, Talebi A, Eshraghi-Jazi F, Mansouri A, et al. Vitamin e is a nephroprotectant agent in male but not in female in a model of Cisplatin-induced nephrotoxicity. ISRN Nephrol. 2013;2013:280395. doi: 10.5402/2013/280395.

23. Nematbakhsh M,Pezeshki Z, Eshraghi-Jazi F, Ashrafi F, Nasri $\mathrm{H}$, Talebi A, et al. Vitamin E, vitamin C, or losartan is not nephroprotectant against cisplatin-induced nephrotoxicity in presence of estrogen in ovariectomized rat model. Int J Nephrol. 2012;2012:284896. doi: 10.1155/2012/284896.

24. Moncada S, Higgs E. The discovery of nitric oxide and its role in vascular biology. Br J Pharmacol. 2006;147;S1:S193201.

25. Beleh MA, Lin YC, Brueggemeier RW. Estrogen metabolism in microsomal, cell, and tissue preparations of kidney and liver from Syrian hamsters. J Steroid Biochem Mol Biol.1995;52;5:479-89.

26. Christo JS, Rodrigues AM, Mouro MG, Cenedeze MA, de Jesus Simões M, Schor N, et al. Nitric oxide (NO) is associated with gentamicin (GENTA) nephrotoxicity and the renal function recovery after suspension of GENTA treatment in rats. Nitric Oxide. 2011;24;2:77-83. doi: 10.1016/j.niox.2010.12.001.

27. Rivas-Cabanero L, Rodriguez-Lopez A, MartinezSalgado C, Saura M, Lamas S, Lopez-Novoa J. Gentamicin treatment increases mesangial cell nitric oxide production.
Exp Nephrol. 1996;5;1:23-30.

28. Ülker S, McKeown PP, Bayraktutan U. Vitamins reverse endothelial dysfunction through regulation of eNOS and NAD (P) H oxidase activities. Hypertension. 2003;41;3:5349.

29. Radermacher J, Klanke B, Schurek H-J, Stolte HF, Frölich JC. Importance of NO/EDRF for glomerular and tubular function: studies in the isolated perfused rat kidney. Kidney Int. 1992;41;6:1549-59.

30. Narita I, Border WA, Ketteler M, Noble NA. Nitric oxide mediates immunologic injury to kidney mesangium in experimental glomerulonephritis. Lab Invest. 1995;72;1:17-24.

31. Walker LM, Walker PD, Imam SZ, Ali SF, Mayeux PR. Evidence for Peroxynitrite Formation in Renal IschemiaReperfusion Injury: Studies with the Inducible Nitric Oxide Synthase Inhibitorl-N 6-(1-Iminoethyl) lysine. J Pharmacol Exp Ther. 2000;295;1:417-22.

32. Baylis C. Nitric oxide deficiency in chronic kidney disease. Am J Physiol Renal Physiol. 2008;294;1:F1-F9. doi: 10.1152/ ajprenal.00424.2007.

33. Ji H, Pesce C, Zheng W, Kim J, Zhang Y, Menini S, et al. Sex differences in renal injury and nitric oxide production in renal wrap hypertension. J Physiol Heart Circ Physiol. 2005;57;1:H43. doi: 10.1152/ajpheart.00630.2004.

Copyright ( $) 2018$ The Author(s); Published by Nickan Research Institute. This is an open-access article distributed under the terms of the Creative Commons Attribution License (http://creativecommons.org/licenses/by/4.0), which permits unrestricted use, distribution, and reproduction in any medium, provided the original work is properly cited. 